\title{
Antigen-specific primed cytotoxic T cells eliminate tumour cells in vivo and prevent tumour development, regardless of the presence of anti-apoptotic mutations conferring drug resistance
}

\author{
Paula Jaime-Sánchez ${ }^{1}$ Elena Catalán ${ }^{2} \cdot$ Iratxe Uranga-Murillo ${ }^{1} \cdot$ Nacho Aguiló $^{3,4} \cdot$ Llipsy Santiago $^{1}$ • \\ Pilar M Lanuza ${ }^{1} \cdot{\text { Diego de } \text { Miguel }^{5} \cdot \text { Maykel A Arias }}^{1} \cdot$ Julián Pardo $\mathbb{D}^{1,3,6,7}$
}

Received: 1 August 2017 / Revised: 20 March 2018 / Accepted: 22 March 2018 / Published online: 9 May 2018

(c) ADMC Associazione Differenziamento e Morte Cellulare 2018

\begin{abstract}
Cytotoxic $\mathrm{CD}^{+} \mathrm{T}(\mathrm{Tc})$ cells are the main executors of transformed and cancer cells during cancer immunotherapy. The latest clinical results evidence a high efficacy of novel immunotherapy agents that modulate Tc cell activity against bad prognosis cancers. However, it has not been determined yet whether the efficacy of these treatments can be affected by selection of tumoural cells with mutations in the cell death machinery, known to promote drug resistance and cancer recurrence. Here, using a model of prophylactic tumour vaccination based on the LCMV-gp33 antigen and the mouse EL4 T lymphoma, we analysed the molecular mechanism employed by Tc cells to eliminate cancer cells in vivo and the impact of mutations in the apoptotic machinery on tumour development. First of all, we found that Tc cells, and perf and gzmB are required to efficiently eliminate EL4.gp33 cells after LCMV immunisation during short-term assays (1-4h), and to prevent tumour development in the long term. Furthermore, we show that antigen-pulsed chemoresistant EL4 cells overexpressing Bcl- $\mathrm{X}_{\mathrm{L}}$ or a dominant negative form of caspase- 3 are specifically eliminated from the peritoneum of infected animals, as fast as parental EL4 cells. Notably, antigenspecific Tc cells control the tumour growth of the mutated cells, as efficiently as in the case of parental cells. Altogether, expression of the anti-apoptotic mutations does not confer any advantage for tumour cells neither in the short-term survival nor in long-term tumour formation. Although the mechanism involved in the elimination of the apoptosis-resistant tumour cells is not completely elucidated, neither necroptosis nor pyroptosis seem to be involved. Our results provide the first experimental proof that chemoresistant cancer cells with mutations in the main cell death pathways are efficiently eliminated by Ag-specific Tc cells in vivo during immunotherapy and, thus, provide the molecular basis to treat chemoresistant cancer cells with CD8 Tc-based immunotherapy.
\end{abstract}

Edited by L. Zitvogel

These authors share first authorship: Paula Jaime-Sánchez, Elena Catalán.

These authors share senior authorship: Maykel Arias, Julián Pardo.

Electronic supplementary material The online version of this article (https://doi.org/10.1038/s41418-018-0112-9) contains supplementary material, which is available to authorised users.

Maykel A Arias

maykelariascabrero@gmail.com

$\triangle$ Julián Pardo

pardojim@unizar.es

1 Biomedical Research Centre of Aragon (CIBA), IIS Aragon/ University of Zaragoza, Zaragoza, Spain

2 Department of Biochemistry and Molecular and Cell Biology, University of Zaragoza, Zaragoza, Spain

3 Dept. Microbiology, Preventive Medicine and Public Health,

\section{Introduction}

Cytotoxic $\mathrm{CD}^{+} \mathrm{T}-\mathrm{Tc}$ cells and Natural Killer-NK cells kill tumoural cells by death ligands (i.e. FasL and TRAIL) or by granule exocytosis, in which the pore-forming protein

\section{University of Zaragoza, Zaragoza, Spain}

4 CIBER Enfermedades Respiratorias, Instituto de Salud Carlos III, Madrid, Spain

5 Centre for Cell Death, Cancer, and Inflammation (CCCI), UCL Cancer Institute, University College London, 72 Huntley Street, London WC1E 6DD, UK

6 Nanoscience Institute of Aragon (INA), University of Zaragoza, Zaragoza, Spain

7 Aragon I+D Foundation, Zaragoza, Spain 
perforin (perf) facilitates the delivery of the serine-proteases granzymes (gzms) into the cytosol of the target cells [1,2]. This mechanism is involved in tumour immunosurveillance and in cancer immunotherapy [2].

From in vitro studies, it seems clear that gzmB presents the highest cytotoxic potential among all gzms and readily induces apoptosis in most types of target cells [1-4]. Several gzmB substrates have been identified in vitro, but only a few of them have been confirmed to be relevant during Tc-mediated and/or NK cell-mediated cell death $[3,5,6]$. GzmB activates apoptosis in vitro by direct cleavage of procaspase 3 to generate the active effector enzyme [7], and by activating the intrinsic mitochondrial pathway, initiated after cleaving Bid to generate the truncated active form $\mathrm{tBid}$ $[8,9]$. The ability of other major gzms such as gzmA or gzmK to induce cell death is still a matter of controversy [6, 10-13], and rather seem to regulate inflammatory pathways [14-20].

Using ex vivo LCMV-specific Tc cells from perf and/or gzm KO mice, we found that perf and gzmB were still able to kill by a caspase-independent and mitochondrialindependent, not yet characterised, pathway [21]. These findings were recently confirmed in humans employing allogeneic-activated NK cells, haematological cancer cell lines and patient-derived samples [22, 23]. Thus, all the in vitro results suggest that activated Tc cells are able to kill tumour cells with acquired drug resistance due to mutations in the apoptotic machinery, and therefore indicate that $\mathrm{Tc}$ cell based-immunotherapy would be very useful to overcome drug resistance in cancer cells. However, since this hypothesis still has not been tested in vivo, its clinical usefulness remains unclear. Seeking to shed more light on this matter, we have used a model of prophylactic tumour vaccination employing the LCMVderived tumour antigen (Ag) gp33 to precisely dissect in vivo the cell death mechanism used by primed Agspecific Tc cells that can only kill through the concerted action of perf and gzmB. We found that, under the conditions where cell death is exclusively executed by perf and gzmB, Tc cells are able to fast and efficiently kill EL4 lymphoma cells overexpressing the anti-apoptotic protein $\mathrm{Bcl}-\mathrm{X}_{\mathrm{L}}$ or a dominant negative form of caspase-3. Moreover, Ag-specific Tc cells were able to prevent long-term tumour development, irrespective of the alterations of the apoptotic machinery.

Our results help to understand the mechanism of Tc cellmediated tumour cell death in vivo during tumour vaccination, indicating that neither the mitochondrial apoptotic pathway nor caspase-3 are required during perf/gzmBmediated tumour cell death in vivo. Furthermore, they provide the first rational physiological basis to treat tumour cells with acquired drug resistance by using immunotherapy based on Tc cells.

\section{Results}

\section{Gp33-specific Tc cells require Perf and gzmB to effeciently eliminate EL4 tumour cells in vivo}

First, a detailed analysis of the relative roles of perf, gzmA and gzmB during cell killing mediated by vaccine-primed gp33-specific Tc cells on EL4 cells in vivo was performed. We employed a well-established model of peritoneal killing in vivo to analyse the relative roles of perf, gzmA and gzmB during cell killing mediated by vaccine-primed gp33-specific Tc cells on EL4 cells (Fig. 1a). Elimination of gp33-pulsed EL4 cells was significantly reduced in mice treated with anti-CD $8 \beta \mathrm{mAb}$ (in which $\mathrm{CD}^{+}{ }^{+} \mathrm{T}$ cells were drastically reduced. Figure $1 \mathrm{~b}$ ), indicating that tumour cells were mostly eliminated by gp33-restricted $\mathrm{CD} 8^{+}$ $\mathrm{T}$ cells.

Once we confirmed that the model was suitable to analyse the elimination of EL4 cells by Ag-specific Tc cells, we sought to establish the minimal immunisation dose of LCMV required to promote the elimination of gp33-pulsed EL4 cells. As shown in Fig. 1c, all animal strains immunised with doses between $10^{2}$ and $10^{4} \mathrm{pfu}$, irrespective of the presence of Perf, gzmA and/or gzmB, were able to eliminate EL4 $4^{\text {gp33.CTGhi }}$ cells to some extent. Perf alone was not enough to induce CTG release in the gp33-pulsed EL4 cells incubated in vitro with gp33-specific Tc cells (data not shown), however, elimination of EL4 cells was less efficient in mice deficient in Perf and both Gzms $\left(\mathrm{PAB}^{-1-}\right)$. Notably, elimination of EL4 cells was almost impaired in $\mathrm{PAB}^{-1-}$ immunised with $10^{1} \mathrm{pfu}$ of LCMV, and was also significantly reduced in mice deficient in $\operatorname{gzmB}\left(\mathrm{gzmB}^{-/-}\right)$, and gzmA and $\mathrm{B}\left(\mathrm{gzmAxB}^{--}\right)$. In contrast, mice deficient in gzmA $\left(\mathrm{gzmA}^{--}\right)$eliminated gp33-pulsed EL4 cells at the same level as wild-type (wt) animals. In light of these results, we decided to analyse the elimination of gp33pulsed EL4 cells at shorter times in mice immunised with $10^{1} \mathrm{pfu}$ of LCMV. As shown in Fig. 1d, $\mathrm{gzmA}^{-1-}$ mice eliminated most target cells already after $1 \mathrm{~h}$ of inoculation. In contrast, elimination of EL4 cells was significantly delayed in $\mathrm{gzmB}^{-1-}$ and $\mathrm{gzmAxB}^{-1-}$ mice. Elimination of gp33-pulsed EL4 cells in $\mathrm{PAB}^{-1-}$ mice was impaired at all time points. Gld mice, expressing a mutated inactive form of FasL, eliminated gp33-pulsed EL4 cells at the same level as wt mice (data not shown), confirming the critical and predominant role of granule exocytosis in the elimination of EL4 cells.

The percentage of gp33-specific Tc cells (tetramer) and gp33-specific degranulating cells (CD107a; Fig. 1e) was not significantly different in the peritoneal cavity of the different immunised mouse strains, discarding that gzmB plays a role during Tc cell migration in this model [24]. 
A. LCMV 端学
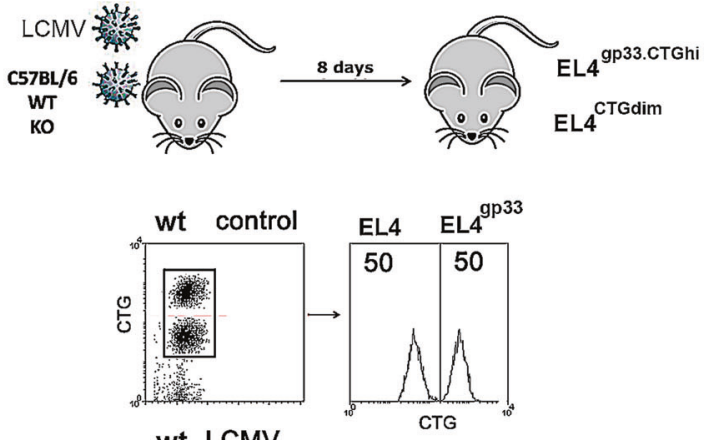

wt LCMV
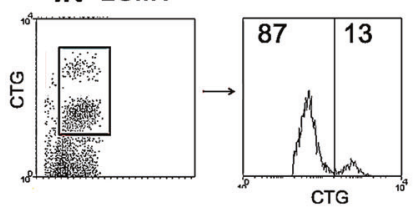

C.

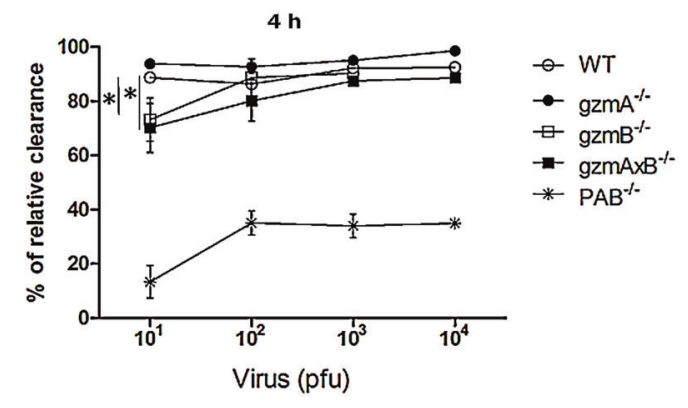

D.

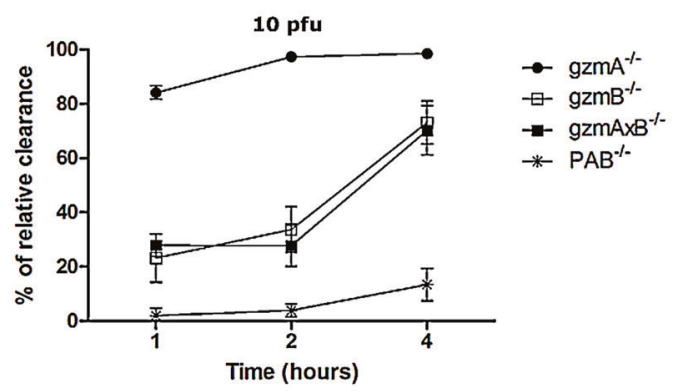

B.

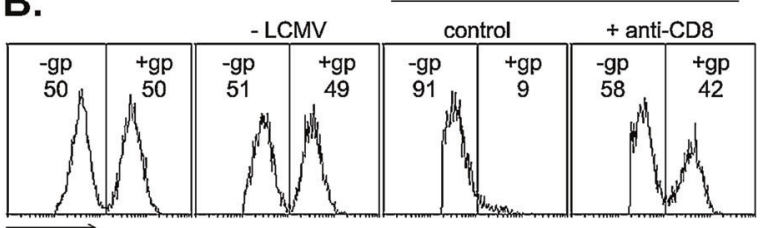
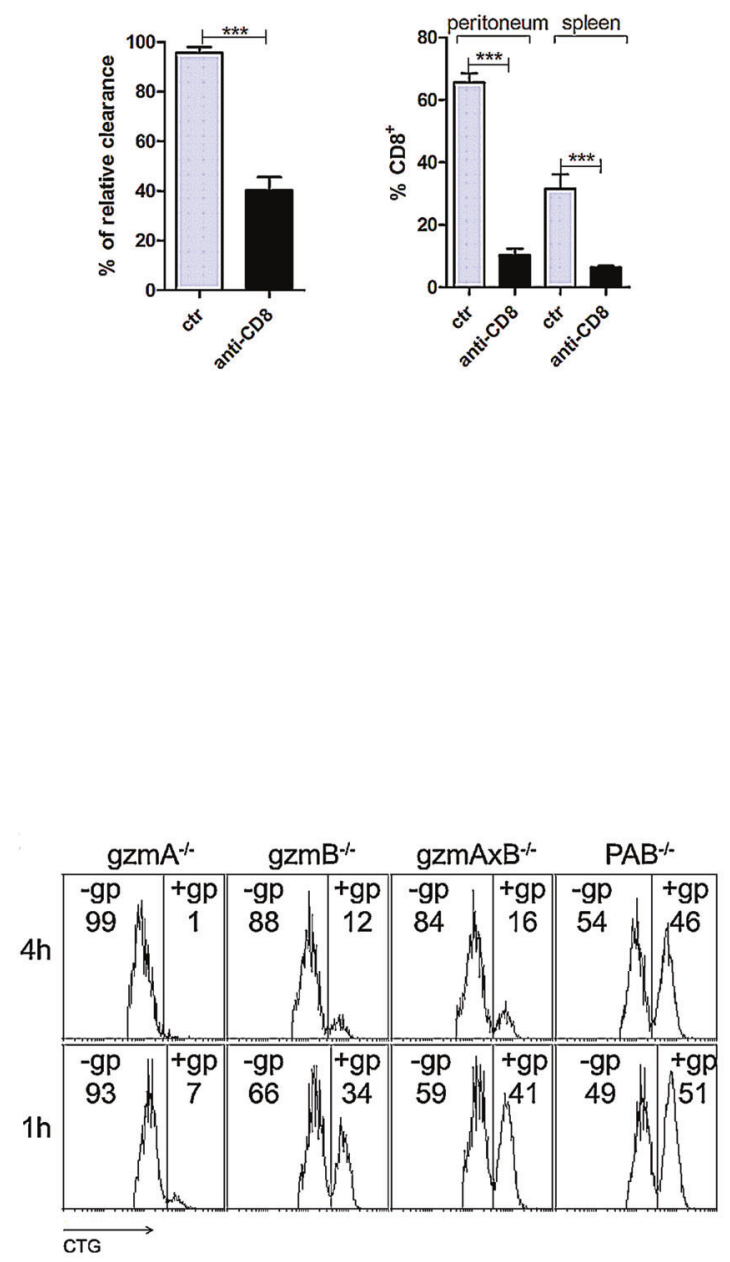

E.
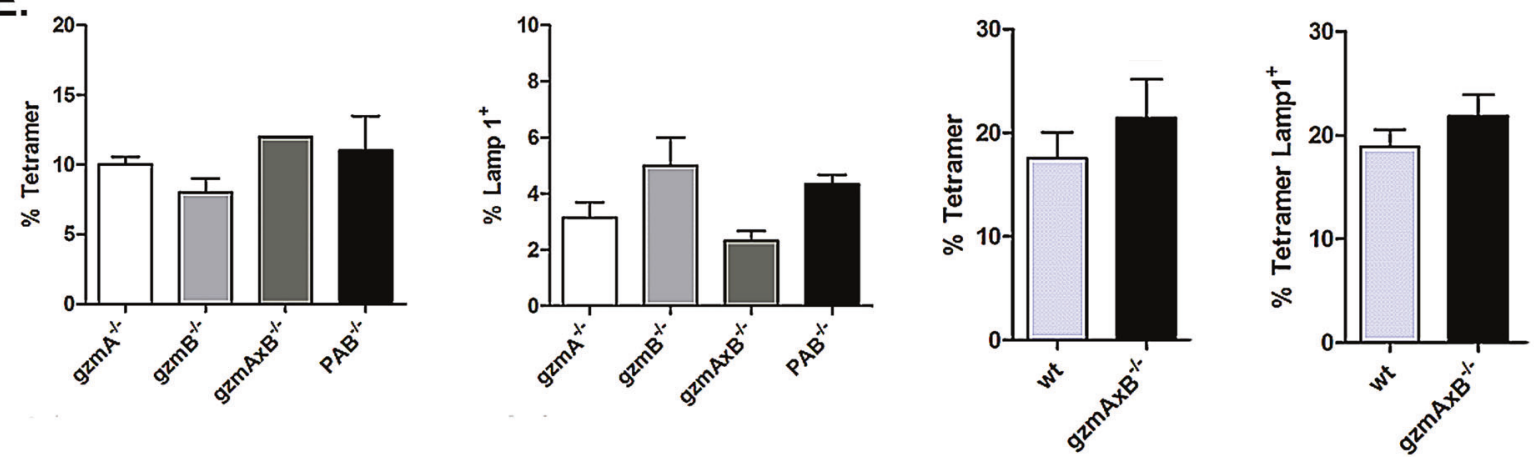
Fig. 1 Perf and gzmB are required for optimal elimination of EL4 tumour cells in vivo by gp33-specific primed Tc cells. a schematic representation of the in vivo peritoneal killing assay. C57B1/6 (B6) wt. or $\mathrm{KO}\left(\mathrm{gzmA}^{-1-}, \mathrm{gzmB}^{-1-}, \mathrm{gzmAxB}^{-1-}\right.$ and $\left.\mathrm{PAB}^{-1-}\right)$ mice are vaccinated or not (control) with LCMV. After 8 days, EL4 cells labelled with two different concentrations of CTG cell tracker, pulsed or not with the LCMV Ag gp33 (EL4 $4^{\text {gp33.CTGhi }}$ and EL4 $\left.{ }^{\text {CTGdim }}\right)$, are inoculated at a ratio $1: 1$ in the peritoneal cavity $\left(1 \times 10^{6}\right.$ cells $)$. Mice are sacrificed at different time points and the relative elimination of EL4 ${ }^{\text {gp 33.CTGhi }}$. A representative example of the analysis in one control (non vaccinated) and one vaccinated (LCMV) mouse is shown. Numbers indicate the percentage of cells, as gated by the vertical bar. The ratio between EL4 ${ }^{\text {gp33.CTGhi }}$ and EL4 ${ }^{\text {CTGdim }}$ cells remains approximately $1: 1$ in non-immunised (Control) animals, meanwhile the peak corresponding to EL4 ${ }^{\text {gp } 33 . C T G h i}$ cells is reduced in LCMVimmunised animals. b wt mice were vaccinated (+LCMV) or not $(-\mathrm{LCMV})$ ) with $10 \mathrm{pfu}$ LCMV at day -8 . Anti-CD8b $(100 \mu \mathrm{g})$ antibody was injected i.p. at days $-4,-2$ and 0 . At day 0 , in vivo peritoneal killing of EL4 cells was analysed after $4 \mathrm{~h}$, as described above. Representative histograms are shown indicating the $\%$ of cells, as gated by the vertical bar. The graph represents the percentage of relative clearance, calculated using the formula $1-\left(\%\right.$ EL4 ${ }^{\text {gp33.CTGhi/ }}$ $\%$ EL4 $\left.{ }^{\text {CTGdim }}\right) \times 100$. In addition, the percentage of $\mathrm{CD}^{+}$cells in the peritoneal cavity and spleen was analysed. Data are represented as the mean $\pm \mathrm{SD}$ of three independent experiments. ${ }^{* * *} P<0,001$. ns no significative; analysed by unpaired $t$-test. c, wt and the indicated $\mathrm{KO}$ mice were vaccinated with decreasing concentrations of LCMV (pfu), and 8 days later in vivo peritoneal killing of EL4 cells was analysed at $4 \mathrm{~h}$, as described above; Data are represented as the mean $\pm \mathrm{SD}$ of four mice from two independent experiments. $* P<0,05$. analysed by unpaired $t$-test. $\mathbf{d}$, wt and the indicated $\mathrm{KO}$ mice were vaccinated with 10 pfu of LCMV, and 8 days later in vivo peritoneal killing of EL4 cells was analysed at different time points, as described above. Data are represented as the mean $\pm \mathrm{SD}$ of six mice from two independent experiments. $* P<0,05$. analysed by unpaired $t$-test. e, wt and the indicated KO mice were vaccinated with $10 \mathrm{pfu}$ of LCMV. After 8 days, the labelled EL4 cells were inoculated and the presence of Agspecific $\mathrm{CD}^{+} \mathrm{T}$ cells (tetramer); degranulating $\mathrm{CD} 8^{+} \mathrm{T}$ cells (Lamp1) and degranulating $\mathrm{Ag}$-specific $\mathrm{CD} 8^{+} \mathrm{T}$ cells (Tetramer Lamp1) was analysed in the peritoneal cavity after $1 \mathrm{~h}$. Data are represented as the mean \pm SD of at least three mice from the two independent experiments

\section{In the absence of gzmA, Ag-specific Tc cells control EL4 tumour development through perf and gzmB}

Our results indicate that under vaccination conditions (10 pfu LCMV), at which wt and $\mathrm{gzmA}^{-/-}$mice completely clear tumour cells, perf and gzmB, but not gzmA, are required for optimal elimination of EL4 cells by Ag-specific Tc cells in vivo at short times. However, it would still be possible that these mice eliminated the remaining gp33pulsed EL4 cells at longer times by alternative mechanisms. To confirm that perf and gzmB are also critical at longer times, we analysed long-term tumour development in mice immunised with 10 pfu of LCMV. Peritoneal gp33-pulsed EL4 tumours developed in all mouse strains that had not been immunised with LCMV, except for $\mathrm{gzmB}^{-1-}$ mice (Fig. 2a). This result is in line with previous findings showing that $\mathrm{gzmB}^{-/-}$, but not $\mathrm{gzmAxB}^{-/-}$, mice are more resistant to syngeneic grafted tumours due to enhanced anti-
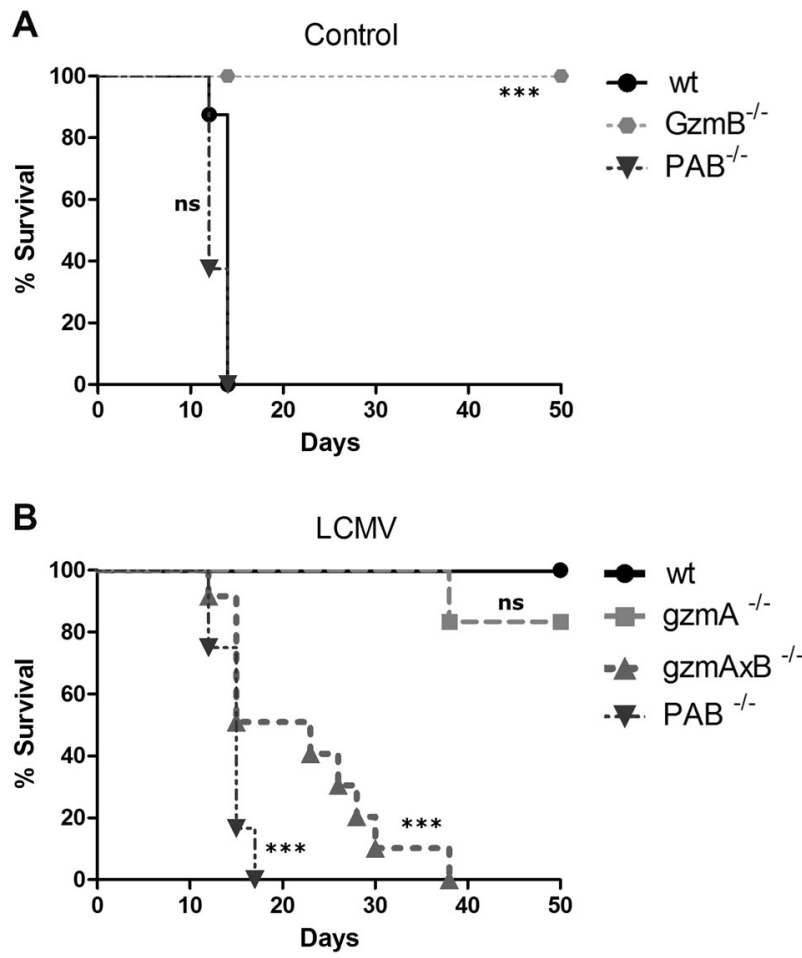

Fig. 2 Intraperitoneal EL4 tumour development in wt and KO mice vaccinated or not with LCMV. wt and the indicated KO mice were non-treated (a) or vaccinated (b) with $10 \mathrm{pfu}$ of LCMV, and 8 days later gp33 pulsed EL4 cells $\left(5 \times 10^{5}\right)$ were inoculated i.p. Tumour development was monitored over 50 days, as described in materials and methods. The data correspond to eight (control) and 12 (LCMV) mice from two and three independent experiments, respectively. $* * * P$ $<0,001$, ns: no significative; analysed by log-rank survival test, comparing each mouse strain to wt mice

tumour Tc cell response, in the absence of Treg-derived gzmB [25]. As shown in Fig. 2b, no tumours were developed in LCMV-immunised wt and gzmA ${ }^{-1-}$ mice $\left(\mathrm{gzmB}^{-1-}\right.$ animals were excluded because of the indicated spontaneous tumour rejection), confirming the results obtained in Fig. 1 at shorter times. In contrast, all gzmAxB ${ }^{-/-}$and $\mathrm{PAB}^{-1-}$ mice developed tumours, and were sacrificed between day 15 and 30. Some LCMV-immunised wt and gzmA ${ }^{-1-}$ mice inoculated with gp33-pulsed EL4 cells were left for 2 months without presenting tumours in the peritoneal cavity or other organs, confirming a complete elimination of tumoural cells (data not shown).

These results indicate that, at least in the absence of gzmA, perf and gzmB are required for the control of EL4 tumour development by primed Ag-specific Tc cells. Notably, they also show that although $\operatorname{gzmAxB}^{-1-}$ mice eliminate a great proportion of gp33-pulsed EL4 cells at short term (Fig. 1d), elimination is not complete and the remaining tumour cells are enough to promote tumour development. Thus, a complete clearance of the tumour 
cells at short times is required to prevent long-term tumour development.

\section{Gp33-specific Tc cells eliminate EL4 cells overexpressing $\mathrm{BCl}-\mathrm{XL}$ or DNC3 in vivo at short time and prevent long-term peritoneal tumour development}

Next, we proposed to find out whether gp33-specific Tc cells were able to overcome in vivo alterations in the apoptotic machinery conferring drug resistance. Thus, by employing the model optimised and characterised above and gzmA ${ }^{-1-}$ mice (to focus on the contribution of the perf/ gzmB pathway), we employed EL4 cells overexpressing anti-apoptotic protein $\mathrm{Bcl}-\mathrm{X}_{\mathrm{L}}$ or expressing a dominant negative form of caspase 3 (DNC3), which confer multidrug resistance and refractoriness, and have been involved in apoptosis induced by gzmB in vitro [1-3]. As shown in Fig. 3a, EL4.Bcl- $X_{\mathrm{L}}$ and EL4.DNC3 cells were completely resistant to doxorubicin, a well-known apoptotic inducer, which correlated with the higher expression of $\mathrm{Bcl}-\mathrm{X}_{\mathrm{L}}$ analysed by western blot or with an impairment to cleave PARP1, a known substrate of caspase-3 (Fig. 3b). EL4 cells transfected with empty vectors behaved similarly as nontransfected cells (data not shown).

Once confirmed their functional drug-resistance phenotype, we analysed in vivo the elimination of the modified cells in the peritoneal cavity of LCMV-immunised mice. As shown in Fig. 3c, gp33-pulsed EL4 cells were almost completely eliminated from the peritoneum of LCMV immunised mice, irrespective of the presence of Bcl- $\mathrm{X}_{\mathrm{L}}$ or DNC3. Notably, the pan caspase inhibitor ZVAD-fmk did not reduce the level of cell killing, even when EL4.Bcl- $X_{L}$ cells were used (data not shown).

Next, we wondered whether these mutations would help EL4 cells to overcome Tc cell-mediated cancer immunotherapy during long-term tumour development. To test the hypothesis, we analysed the long-term peritoneal EL4 tumour development in gzmA $^{-1-}$ mice vaccinated with 10 pfu of LCMV and challenged with gp33pulsed EL4 cells. As shown in Fig. 3d, no tumour was detected in any vaccinated animal, and all mice survived irrespectively of whether they had been inoculated with parental EL4 cells or with EL4.Bcl-X $\mathrm{L}_{\mathrm{L}}$ or EL4.DNC3 cells. Notably, EL4 modified cells retained their functional apoptotic resistance during tumour growth, since cells recovered from the peritoneal tumours after 3 weeks were still resistant to doxorubicin (Fig. 3e). Moreover, EL4.Bcl- $\mathrm{X}_{\mathrm{L}}$ tumours also presented resistance to doxorubicin treatment in vivo (Fig. 3f). These results confirm that Ag-specific Tc cells eliminate chemoresistant EL4 cells in vivo at short term and prevent long-term tumour development.

\section{Neither inhibition of necroptosis nor inhibition of pyroptosis protects EL4 cells from cell death induced by ex vivo gp33-specific Tc cell}

To find out the mechanism by which Ag-specific Tc cells eliminate apoptosis-resistant tumour cells, we analysed the possible involvement of other types of cell death under those circumstances. Gp33-specific Tc cells were able to induce caspase 3 activation, as well as mitochondrial membrane depolarisation $\left(\Delta \Psi_{\mathrm{m}}\right.$ loss $)$ in EL4.wt cells, confirming that cells were dying by the classical pathways activated by gzmB (Fig. 4a, b, low panel) [26]. Apoptosis induced by gp33-specific gzmB $^{+}\left(\mathrm{gzmA}^{-1-}\right)$ Tc cells was not affected by Bcl- $\mathrm{X}_{\mathrm{L}}$ overexpression or by the presence of DNC3 (Fig. 4b), indicating that gp33-specific Tc cells were also able to overcome anti-apoptotic drug resistance mutations in vitro. Neither $\mathrm{Bcl}-\mathrm{X}_{\mathrm{L}}$ overexpression nor the presence of DNC3 affected mitochondrial depolarisation (Fig. 4b, low panel), confirming that cell death induced by gp33-specific Tc cells was independent of the mitochondrial-apoptotic pathway.

It should be noted that, in our model, Tc cell-mediated cell death in vitro and in vivo, as well as control of tumour development strictly depends on perf expression, which discards necroptosis induced by death ligands as a relevant mechanism during the elimination of apoptosis-resistant EL4 cells. Thus, our hypothesis was that a non-apoptotic perf/gzmB-dependent cell death pathway would be activated during tumour elimination mediated by $\mathrm{Ag}$-specific Tc cells. To address that, we first analysed the effect of the RIP1 kinase inhibitor necrostatin-1 (Nec-1) that blocks necrosome formation [27] and of the caspase-1 inhibitor VX-765 (inhibitor of pyroptosis [28]) on cell death induced by LCMV-specific Tc cells ex vivo. As shown in Fig. 4c, the general caspase-inhibitor Q-VD-OPh shows a slight effect on cell death induced by Tc cells on gp33-pulsed EL4 cells. This effect was time dependent, since after $20 \mathrm{~h}$, QVD-OPh has no effect on Tc cell-induced cell death (Data not shown). Nec-1 did not show any protective effect, even when it was combined with Q-VD-OPh. It has been recently suggested that RIPK1 could block RIPK3-dependent necroptosis under certain circumstances. To confirm the efficacy of Nec-1 in our model, we analysed TNF $\alpha$-induced cell death in L929 cells, a cell type that preferentially undergoes necroptosis in response to this cytokine [29]. TNF $\alpha$ was combined with the small molecule SM83, a known inhibitor of XIAP and cIAP1/2, which has been shown to favour necroptotic cell death [30]. As previously found in other cell types [30, 31], SM83 alone induced a significant level of cell death in L929 cells. As shown in Fig. 4c (right panel), the combination of SM83 with TNF $\alpha$ induced high level of cell death in L929 cells that predominantly presented a necrotic phenotype $\left(7 \mathrm{AAD}^{+}\right.$; 
compare TNF $\alpha / \mathrm{SM} 83$ vs. SM83 alone). The presence of necrotic $7 \mathrm{AAD}^{+}$cells was almost completely inhibited by Nec-1, both in the absence or presence of the general caspase inhibitor Q-VD-OPh. In contrast to L929 cells, necroptosis was not induced in EL4 cells, even at very high doses of $\mathrm{TNF} \alpha(500 \mathrm{ng} / \mathrm{ml})$ in the presence of SM83. Thus, Tc cells do not induce necroptosis on apoptosis-resistant EL4 cells
A

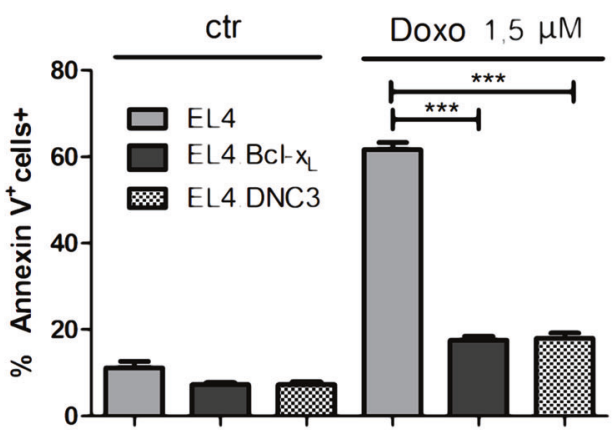

B
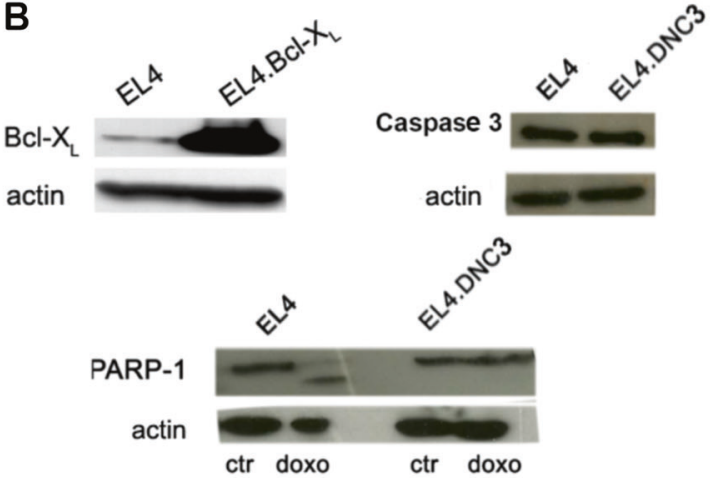

C

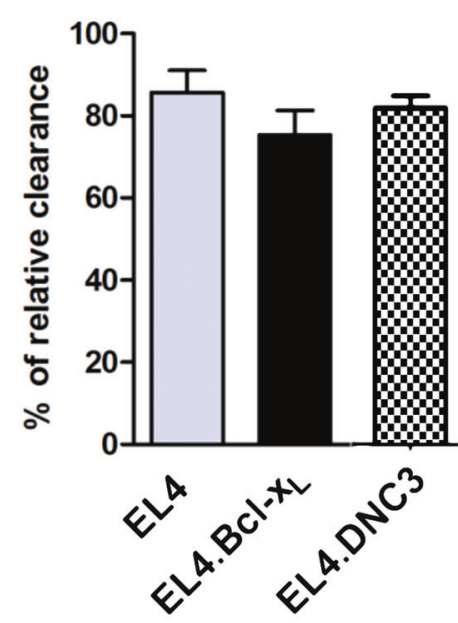

D

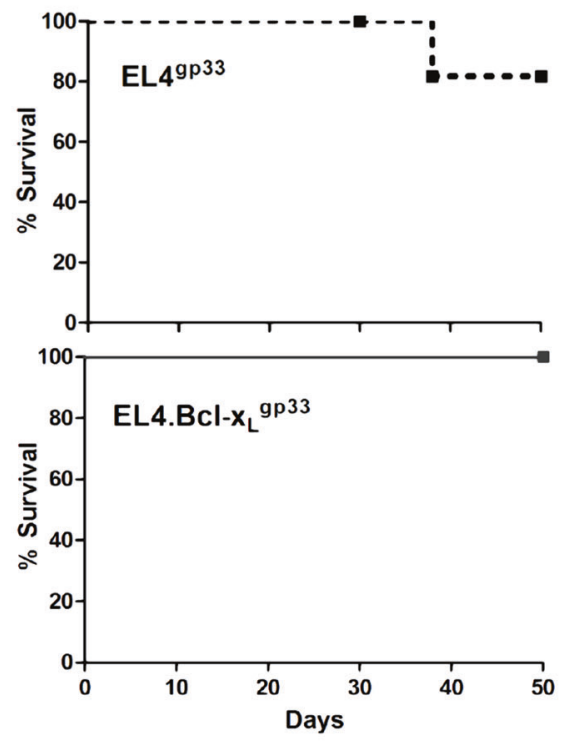

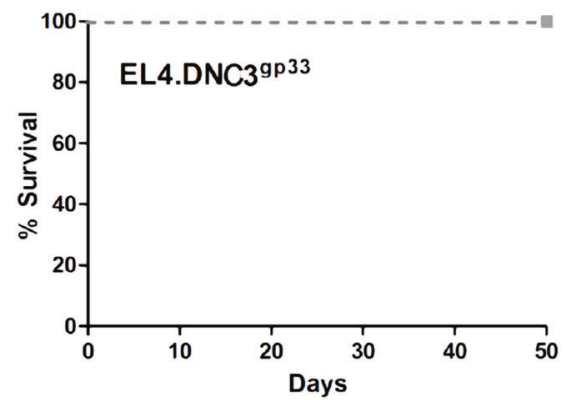

E

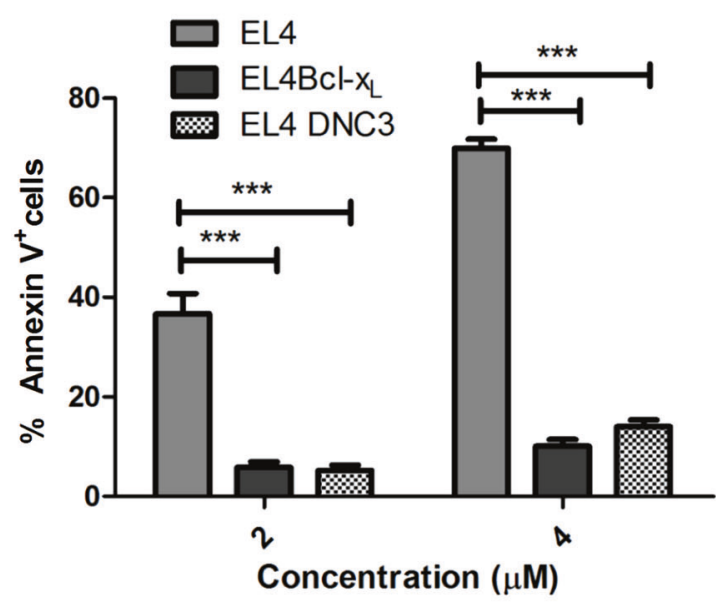

F

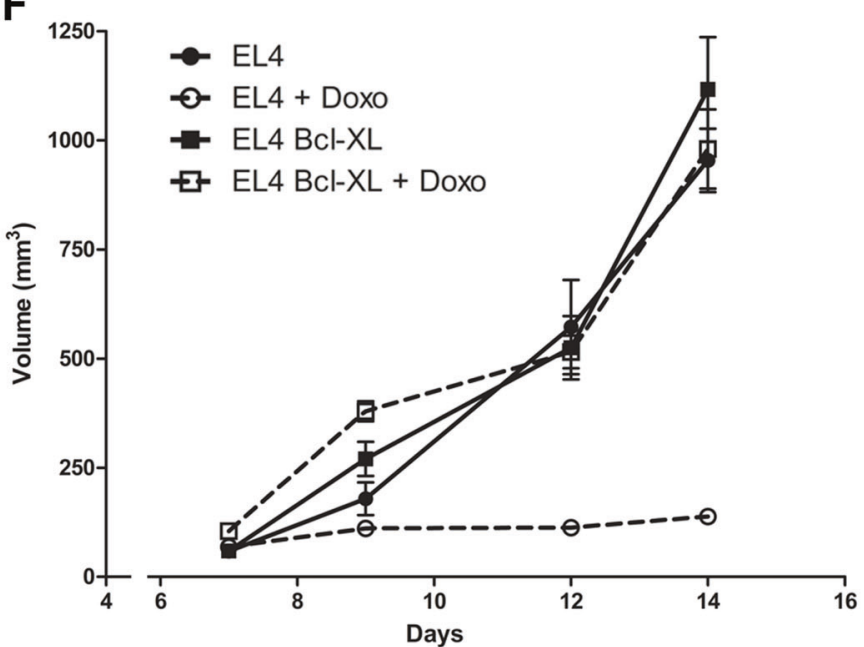


Fig. 3 Overexpression of Bcl-XL or a dominant negative mutant of caspase 3 does not confer resistance to gp33-specific primed Tc cells in EL4 cells in vivo. a and b Parental EL4 cells or EL4 cells overexpressing $\mathrm{Bcl}-\mathrm{X}_{\mathrm{L}}$ or a dominant negative mutant of caspase 3 (DNC3) were non-treated (control) or incubated with doxorubicin 1.5 $\mu \mathrm{M}$ (dox) for $24 \mathrm{~h}$. Subsequently (a), PS traslocation was analysed by Annexin V staining, as described in materials and methods. Data are represented as the mean $\pm \mathrm{SD}$ of three independent experiments. $* * * P$ $<0,001$ analysed by unpaired $t$-test. In parallel $(\mathbf{b}), \mathrm{Bcl}-\mathrm{X}_{\mathrm{L}}$, caspase 3 (zymogen) and PARP-1 were analysed by western blot, as indicated in materials and methods. b-Actin was used as loading control. $\mathbf{c}$ gzmA ${ }^{-/}$mice were vaccinated with $10 \mathrm{pfu}$ of LCMV, and 8 days later in vivo peritoneal killing of parental EL4, EL4.Bcl- $\mathrm{X}_{\mathrm{L}}$ and EL4.DNC3 cells was analysed at $4 \mathrm{~h}$, as described in Fig. 1; Data are represented as the mean $\pm \mathrm{SD}$ of four mice from two independent experiments. $* P$ $<0,05$ analysed by unpaired $t$-test. Representative histograms are shown on the right panels. Numbers correspond to the percentage of cells, as gated by the vertical bars. d, gzmA ${ }^{-1-}$ mice were vaccinated with 10 pfu of LCMV, and 8 days later gp33-pulsed EL4 cells $(5 \times$ $10^{5}$ ) were inoculated i.p. Tumour development was monitored over 50 days, as described in materials and methods. The data correspond to 12 mice from three independent experiments. e, Cells were recovered from the peritoneal tumours of non-vaccinated mice that had been previously inoculated with parental EL4, EL4.Bcl-X $\mathrm{L}_{\mathrm{L}}$ and EL4.DNC3 cells. Subsequently, they were incubated with 2 or $4 \mu \mathrm{M}$ doxorubicin for $24 \mathrm{~h}$, and PS traslocation was analysed by Annexin V staining. Data are represented as the mean $\pm \mathrm{SD}$ of two independent experiments. The control values for the $\%$ Annexin $\mathrm{V}^{+}$cells in non-treated cultures (less than $10 \%$ in all cases) were subtracted. $* * * P<0,001$. Analysed by unpaired $t$-test. F, $1 \times 10^{5}$ EL4 and EL4.Bcl-X $\mathrm{X}_{\mathrm{L}}$ cells were inoculated s.c. in $\mathrm{C} 57 \mathrm{~B} 1 / 6$ (B6) wt mice. When tumours reached a volume of $50 \mathrm{~mm} 3$, they were treated with intratumoural doxorubicin (4 mg/kg; days 7, 9 and 12), and tumour growth was monitored daily, as described in materials and methods. Mice were sacrificed when control groups reached the humane endpoint ( 2 weeks). The data correspond to 9 (EL4), 12 (EL4.Bcl-XL; EL4/Doxo) or 14 (EL4.Bcl$\mathrm{XL} / \mathrm{Doxo})$ mice

As shown in Fig. 4d, IL1 $\beta$ release was significantly increased in the supernatant of gp-33 pulsed EL4 cells after $20 \mathrm{~h}$ of incubation with LCMV-specific Tc cells, which was significantly reduced by the caspase-1 inhibitor VX-765. However, cell death was not affected by VX-765, indicating that although caspase- 1 is activated, pyroptosis is not involved in cell death induced by ex vivo Ag-specific Tc cells.

\section{Gp33-specific Tc cells prevent long-term EL4 tumour development after subcutaneous (SC) inoculation}

Finally, we confirm our results in vivo on a SC tumour model as shown in Fig. 5a. In order to rule out a possible contribution of FasL to tumour control, we also included gld mice that express FasL in an inactive mutated form.

As shown in Fig. 5a, non Ag-pulsed EL4 tumours developed in all mouse strains, irrespective of the presence of perf and/or gzms. GzmB ${ }^{-1-}$ mice did not develop tumours after s.c. inoculation (data not shown), as shown in the i.p. route. A similar result was found when B16 melanoma cells were used, confirming that this effect was not restricted to EL4 tumours (data not shown). In contrast to non-pulsed tumours, gp33-pulsed EL4 tumours did not develop in wt, gld and $\mathrm{gzmA}^{-1-}$ mice. In contrast, all gzmAxB ${ }^{-1-}$ and $\mathrm{PAB}^{-1-}$ mice developed tumours and were sacrificed at around day 17. A similar result was found using B16 melanoma cells (figure S1). Overall, these results confirm that the control of EL4 (and B16) tumours in vivo by Ag-specific Tc cells is mainly mediated by perf and gzmB, whereas gzmA, FasL and other death ligands are dispensable.

As shown in Fig. 5b, LCMV vaccinated mice were successfully able to reject tumour growth of gp33-pulsed EL4, EL4.Bcl-X $\mathrm{L}_{\mathrm{L}}$ or EL4.DNC3 cells, whilst all animals developed tumours in the flank inoculated with non-pulsed cells. These results confirmed that Ag-specific Tc cellmediated elimination is not prevented by expression of drug resistance mutations such a $\mathrm{Bcl}-\mathrm{X}_{\mathrm{L}}$ or by the loss of caspase-3 activity.

\section{Discussion}

Cytotoxic T (Tc) cells are crucial for an efficient elimination of tumour cells in both immunosurveillance and immunotherapy. Employing an immunotherapy model of tumour vaccination, we show here that primed Ag-specific Tc cells efficiently eliminate tumour cells in vivo and prevent long-term tumour development, even in those cells expressing multidrug resistance due to alterations in the apoptotic machinery such as overexpression of Bcl- $\mathrm{X}_{\mathrm{L}}$ or expression of a dominant negative form of caspase- 3 . Thus, our results bear high biological and clinical relevance, demonstrating in in vivo settings the Tc cellmediated immunotherapy, and more specifically cell death induced by perf and gzmB secreted by those Tc cells, are useful to treat apoptosis-resistant tumour cells, and could be clinically exploited to treat tumours with acquired drug resistance.

Although we have employed a viral Ag-based tumour model, our results could be extrapolated to other cancer immunotherapy approaches based on viral infections (i.e. oncolytic viruses), since the affinity of the antigen $\mathrm{T}$ cell receptor for viral gp33 is similar to common tumour antigens such as MelanA, NYESO or gp100 [32, 33]. This affinity is even higher for engineered, high-affinity $\mathrm{T}$ cell receptors that could be used to create CAR-T cell therapies against tumour neoantigens.

We haven't been able so far to completely decipher the specific molecular mechanism underlying this type of nonapoptotic cell death, we can affirm that neither necroptosis nor pyroptosis are involved. In fact, cell death induced by Tc cells ex vivo on apoptosis-deficient cells was not 
A

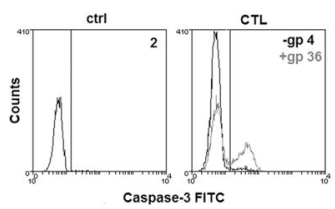

B
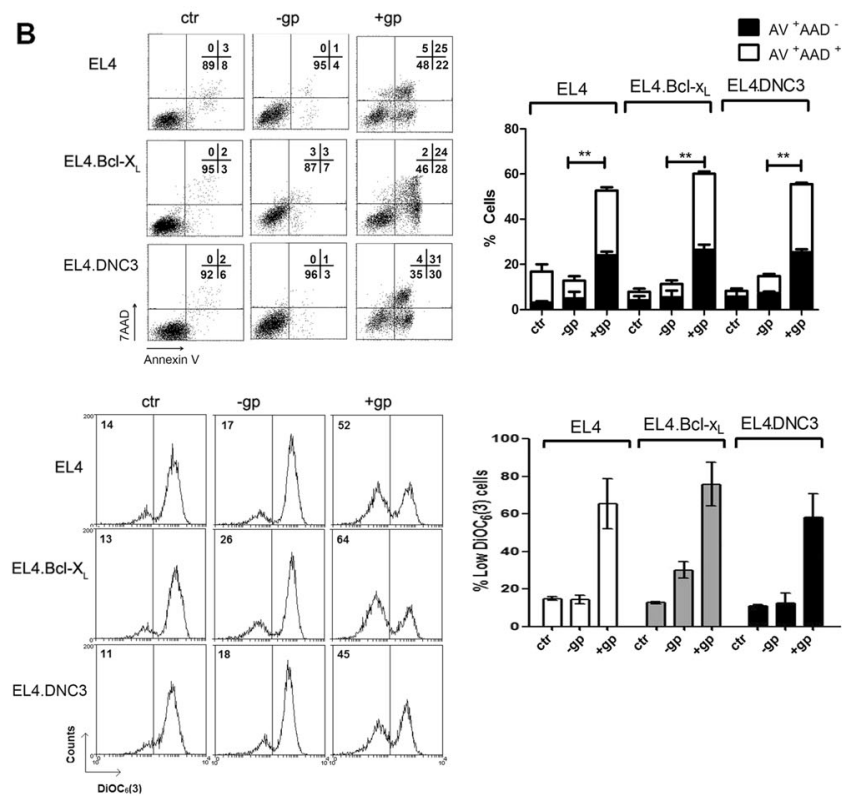

C
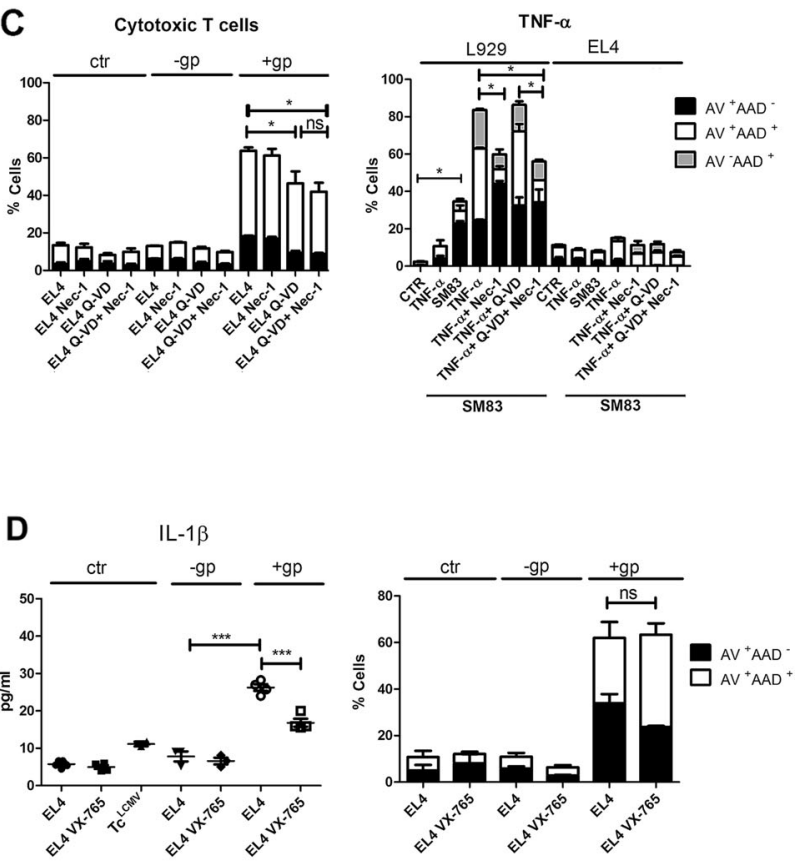

Fig. 4 Cell death induced by gp33-specific primed Tc cells on EL4 cells is not affected by Bcl-XL overexpression or caspase and RIPK1 inhibition. a Parental EL4 cells were incubated with ex vivo virus immune $\mathrm{CD}^{+}$cells from $\mathrm{gzmA}^{-1-}$ mice in the presence $(+\mathrm{gp})$ or absence (-gp) of the peptide gp33 for $2 \mathrm{~h}$ at a $e$ :t ratio 10:1. Activation of caspase 3 was monitored with an FITC-labelled mAb against the active form of the enzyme. Histograms show a representative experiment. Numbers correspond to the percentage of cells, as indicated by the horizontal bars. b Parental EL4, EL4.Bcl- $\mathrm{X}_{\mathrm{L}}$ and EL4.DNC3 cells were incubated with ex vivo virus immune $\mathrm{CD} 8^{+}$cells from $\mathrm{gzmA}^{-1-}$ mice in the presence $(+g p)$ or absence $(-g p)$ of the peptide gp33 for 2 $\mathrm{h}$ at a $e: t$ ratio 10:1. Subsequently, PS exposure on plasma membrane (annexin-V-FITC), 7AAD uptake (upper panel) and $\Delta \Psi_{\mathrm{m}}$ loss (DiOC6 (3); lower panels) were analysed by three-colour flow cytometry in the target cells (CTG negative), as described in Materials and Methods. Representative dot plot and histogram analysis are shown. Numbers correspond to the percentage of cells in each quadrant or gated by the vertical bars. Data are represented as the mean \pm SD of three (annexinV/7AAD) and two (DiOC6(3); lower panels) independent experiments. ${ }^{*} P<0,01$. Analysed by unpaired $t$-test. C, Left panel. EL4 cells were incubated with ex vivo virus immune $\mathrm{CD}^{+}$cells, as

affected by neither inhibition of necroptosis nor inhibition of pyroptosis. In vitro gzmB is able to degrade dozens of substrates [1, 3, 21, 34-39]. Although most of them have not been validated employing intact cytotoxic effector cells, this pleiotropism would support our results indicating that primed Ag-specific Tc cells control the development of tumours overexpressing proteins that block the mitochondrial-dependent $\left(\mathrm{Bcl}-\mathrm{X}_{\mathrm{L}}\right)$ or caspase-dependent (DNC3 or caspase inhibitors) cell death pathways. In this regard, our data are in line with previous ex vivo findings, indicating that Tc cell-derived Perf and gzmB are able to indicated in $\mathrm{A}$ in the absence or presence of the pan caspase inhibitor QVD $(30 \mu \mathrm{m})$, the RIPK1 inhibitor necrostatin-1 $(30 \mu \mathrm{M})$ or a combination of both. PS exposure on plasma membrane (annexin-V-FITC) and 7AAD uptake were analysed by three-colour flow cytometry in the target cells (CTG negative), as described in Materials and Methods. Right panel, L929 and EL4 cells were non-treated (ctr) or incubated with TNF $\alpha(50 \mathrm{ng} / \mathrm{ml} \mathrm{L929;} 500 \mathrm{ng} / \mathrm{ml} \mathrm{EL4})$ in the absence or presence of the SMAC mimetic SM-83 $(100 \mathrm{nM})$ alone or in combination with QVD and/or Nec-1. After $20 \mathrm{~h}$, PS exposure on plasma membrane (annexin-V-FITC) and 7AAD uptake were analysed by flow cytometry, as described in Materials and Methods. Data are represented as the mean \pm SD of three independent experiments. $* P<0,05$, ns: no significative; Analysed by unpaired $t$-test. D, EL4 cells were incubated with ex vivo virus immune $\mathrm{CD}^{+}$cells, as indicated in $\mathrm{A}$ in the absence or presence of the caspase 1 inhibitor VX-765 $(30 \mu \mathrm{m})$. After $4 \mathrm{~h}$, PS exposure on plasma membrane (annexin-V-FITC) and $7 \mathrm{AAD}$ uptake (right panel) were analysed by three-colour flow cytometry in the target cells (CTG negative) and IL1 $\beta$ release (left panel) in the cell supernatant by ELISA, as described in Materials and Methods. $* * P<0,001$. Analysed by unpaired $t$-test

activate cell death pathways independently on the mitochondria and caspases [1, 3, 21, 37, 38].

Other gzms such as gzmA and gzmK could contribute to the control of drug-resitant tumour cells although its ability to induce cell death is highly controversial controversial $[1,2,11,13,39,40]$. Our in vivo data employing several KO mice and two different tumour models, confirm previous in vitro findings suggesting that mouse gzmA and gzmK present very low cytotoxicity against tumour cells and are dispensable for tumour control $[1,2,11,13,15,16$, $36,39,40]$. Moreover, although contradictory results have 
A

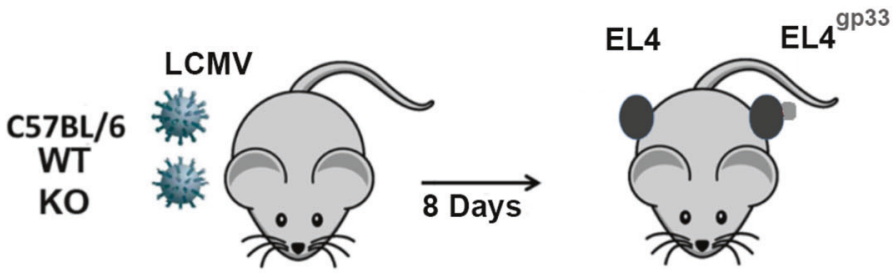

EL4 cells

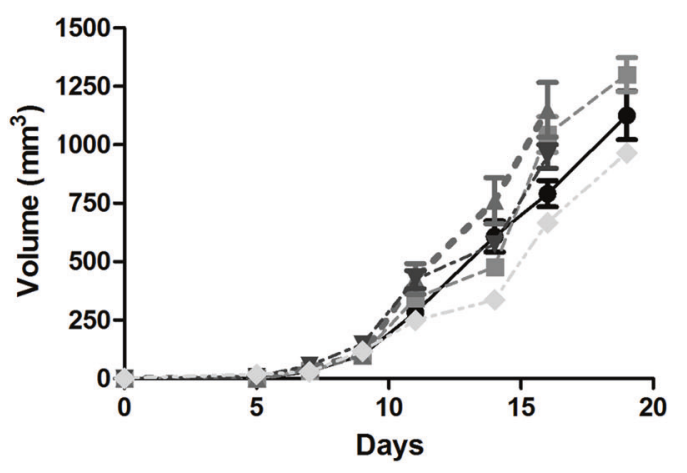

\section{EL4 ${ }^{\mathrm{gp} 33}$ cells}

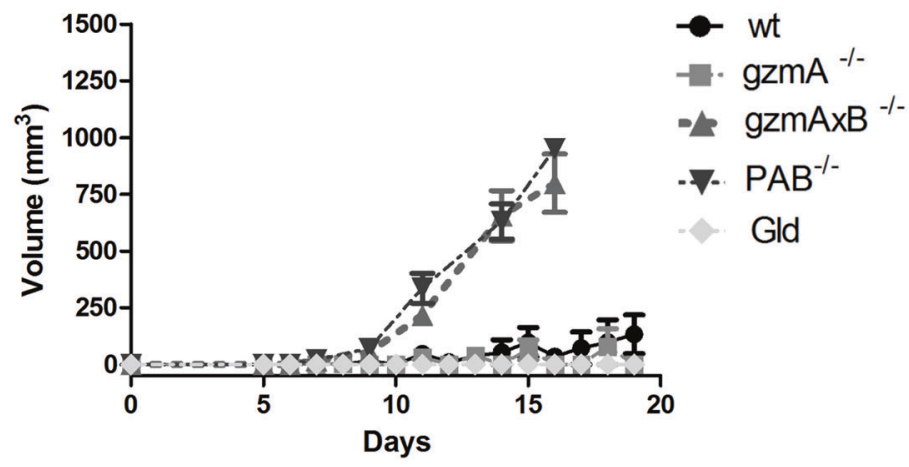

B

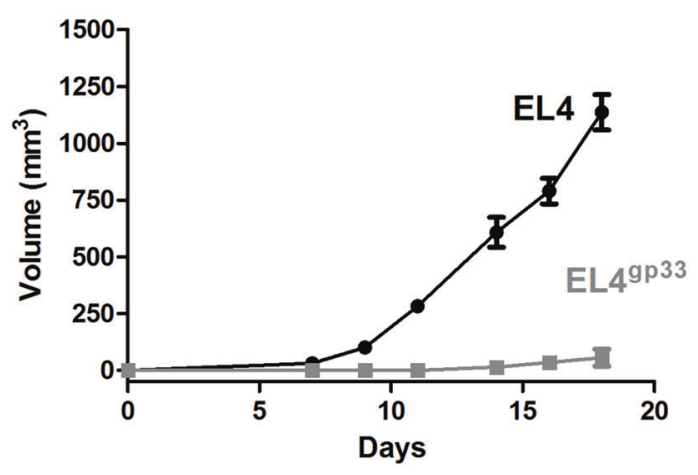

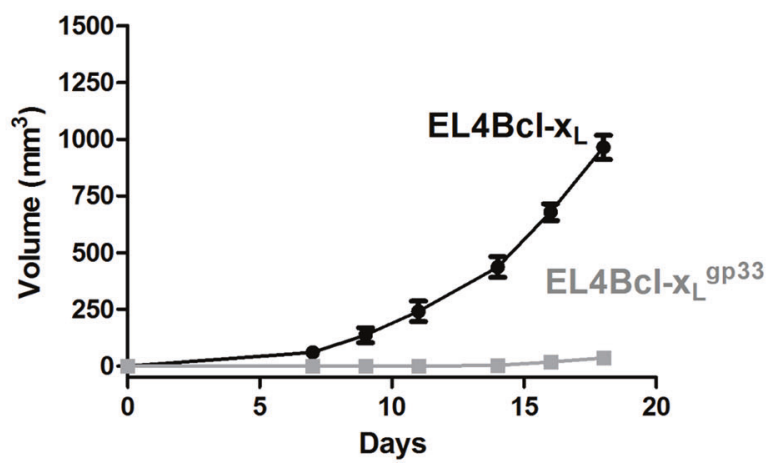

Fig. 5 gp33-specific primed Tc cells prevent development of subcutaneous EL4 tumours overexpressing Bcl-XL and DNC3 mutations. a The upper panel shows a schematic representation of the subcutaneous tumour model. To confirm that the elimination of EL4 cells was mediated by Ag-specific Tc cells and to reduce the number of animals, we employed LCMV-immunised mice, in which EL4 and gp33-pulsed EL4 cells were inoculated in the left and right flanks, respectively. C57B1/6 (B6) wt, $\mathrm{KO}\left(\mathrm{gzmA}^{-/-}, \mathrm{gzmB}^{-/-}\right.$, $\mathrm{gzmAxB}^{-/-}$ and $\mathrm{PAB}^{-l-}$ ) or mutated (gld) mice are vaccinated with $10 \mathrm{pfu}$ LCMV. After 8 days, $2 \times 10^{5}$ EL4 cells pulsed or not with the LCMV Ag gp33

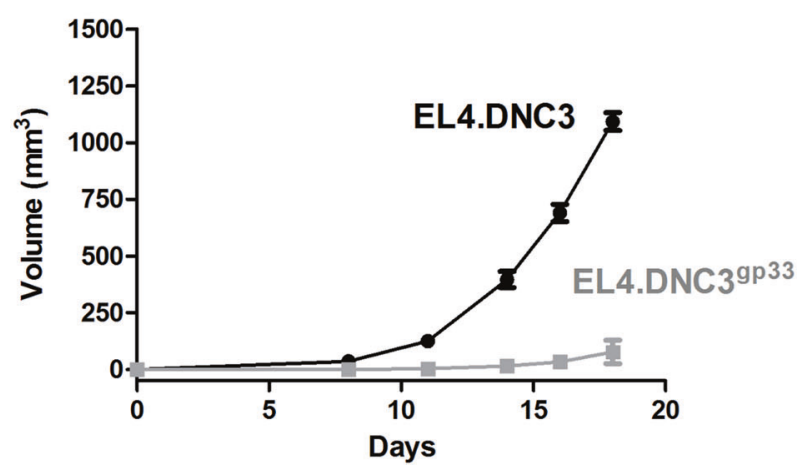

$\left(E L 4^{\mathrm{gp} 33}\right.$ and EL4) are inoculated on the left and right flanks of mice, respectively. Tumour development was monitored over 20 days, as described in materials and methods. The data correspond to 12 mice from three independent experiments. b parental EL4, EL4.Bcl- $\mathrm{X}_{\mathrm{L}}$ and EL4.DNC3 tumour development were analysed in vaccinated mice, as described in A. Since wt and $\mathrm{gzmA}^{-1-}$ mice are indistinguishable when inoculated with EL4 tumours i.p or s.c and following the guidelines of our institutional ethics committee, we only employed wt mice as control 
been reported concerning the role of gzmA and gzmB in tumour immunosurveillance [25, 41-44], the role of these proteases during tumour vaccination has not been previously tested. In this line, we have found that $\mathrm{gzmB}^{-/-}$and gzmAxB $^{-l-}$ mice are not able to control long-term tumour development

In contrast to our results, employing a human colorectal cancer (HCT116 cells) xenograft model in nude mice, Ravi et al reported that overexpression of $\mathrm{Bcl}-\mathrm{X}_{\mathrm{L}}$ conferred resistance to immune cell-mediated elimination of tumours cells in vivo [45]. However, that study analysed the elimination of human tumour cells employing adoptive cell therapy with mouse splenocytes as effector cells. Unfortunately, the findings have not been confirmed employing human immune effector cells in vivo or humanised mice and are not directly comparable with our results. Importantly, it should be noted that human and mouse gzmB presents different substrate affinity [1, 3, 21, 34-39]. Meanwhile, mouse purified gzmB has preferential affinity for caspase 3, human purified gzmB preferentially activates the mitochondrial cell death pathway via Bid [9, 36, 46-48]. Thus, different results could be find when using human and mouse Tc cells. However, and supporting our findings in mice, it has been found that human Tc and NK cells are also able to kill tumour cells in vitro overexpressing $\mathrm{Bcl}-\mathrm{X}_{\mathrm{L}}$ or Bcl-2 [22, 49], although in this case the specific contribution of gzmB was not addressed.

During the last years, new immunotherapy protocols have been developed to re-activate the anti-tumoural $\mathrm{CD} 8^{+}$ $\mathrm{T}$ cell response by blocking the inhibitory immune check points CTLA4 and PD1/PDL1 [50, 51]. These protocols have shown unprecedented high efficacy against bad prognosis cancers such as melanoma or lung carcinoma [52-55]. Of note these $\mathrm{mAb}$ are used as first-line treatment in melanoma and non-small cell lung carcinoma (NSCLC). Although the whole picture of the cellular mechanism induced by these $\mathrm{mAb}$ is not completely clarified [56], CD8

${ }^{+} \mathrm{T}$ cells are the main effector cells responsible of tumour elimination during these treatments. Curiously, in both types of cancer melanoma and NSCLC, overexpression of $\mathrm{Bcl}-\mathrm{X}_{\mathrm{L}}$ has been shown to be a bad prognosis factor and a determinant of drug resistance [57-63], although the correlation of $\mathrm{Bcl}-\mathrm{X}_{\mathrm{L}}$ overexpression and $\mathrm{mAb}$ therapy efficacy has not been analysed. Our results indicate that an efficient priming of an $\mathrm{Ag}$-specific $\mathrm{CD}^{+} \mathrm{T}$ cell response against tumour cells is able to overcome overexpression of $\mathrm{Bcl}-\mathrm{X}_{\mathrm{L}}$, explaining in part why despite overexpressing $\mathrm{Bcl}-\mathrm{X}_{\mathrm{L}}$, these cancer types respond very well to CTLA4 and/or PD1/ PDL1 mAb therapy. In this line a recent study found a positive correlation between PDL1 and $\mathrm{Bcl}-\mathrm{X}_{\mathrm{L}}$ expression in tumour cells, in patients with NSCLC [64]. Although this correlation had no impact in the prognostic value, this study did not include the response to PDL1/PD1 therapy. Since
PDL1 expressing tumour cells are the main targets eliminated by $\mathrm{CD} 8^{+} \mathrm{Tc}$ cells during anti-PDL1 mAb therapy, it could be speculated that endogenous activated Tc cells are able to overcome Bcl- $\mathrm{X}_{\mathrm{L}}$ overexpression in NSCLC cells. However, more studies will be required to formally show the correlation between $\mathrm{Bcl}-\mathrm{X}_{\mathrm{L}}$ overexpression in tumour cells and the response to $\mathrm{CD}^{+} \mathrm{T}$ cell-mediated immunotherapy in humans.

In conclusion, we show that vaccination against a tumour $\mathrm{Ag}$ model generates a $\mathrm{CD} 8^{+} \mathrm{Tc}$ cell response that controls development of the EL4 lymphoma model by a mechanism dependent on perforin and, probably, granzyme B, independently of granzyme A and death ligands. Primed Agspecific $\mathrm{CD}^{+} \mathrm{Tc}$ cells are able to overcome mutations in cell death pathways known to confer multidrug resistance and prevent the generation of tumours in vaccinated animals. Pending of validation employing conventional clinically-adopted immunotherapy protocols like DC vaccination or immune checkpoint mAbs and other tumour models our findings provide the first molecular basis for the rational use of immunotherapy in multidrug resistant tumours due to mutations in the apoptotic machinery.

\section{Materials and methods}

\section{Mouse strains}

Inbred C57Bl/6 (B6), and mouse strains deficient for gzmA $\left(\mathrm{gzmA}^{---}\right), \operatorname{gzmB}\left(\mathrm{gzmB}^{---}\right), \operatorname{gzmAxB}\left(\mathrm{gzmAxB}^{-{ }^{-}}\right)$and perfxgzmAxgzmB $\left(\mathrm{PAB}^{-1-}\right)$, bred on $\mathrm{B} 6$ background were maintained at the Centre for Biomedical Research of Aragon (CIBA), and analysed for their genotypes as described [42]. Mice of 8-10 weeks of age were used in all experiments and were performed in accordance FELASA guidelines under the supervision and approval of Comité Ético para la Experimentación Animal (Ethics Committee for Animal Experimentation) from the University of Zaragoza (number: PI33/13).

\section{Cell lines, cell culture and reagents}

EL4, EL4.DNC3 and EL4.Bcl- $\mathrm{X}_{\mathrm{L}}$ cells were cultured in RPMI with 5\% heat-inactivated fetal bovine serum (FBS) at $37^{\circ} \mathrm{C}$. EL4 cells overexpressing Bcl-XL or expressing a dominant negative mutant of caspase-3 (Cys285Ala; DNC3; Genscript) [65] were generated by lentiviral infection employing the pBABE-puro vector containing the cDNA of the proteins and the psPAX and pMD2.G vectors containing the HIV-1 Gag and Pol and VSV Env proteins, respectively. Transfected cell clones were selected by limiting dilution employing conditioned medium and puromycin as antibiotic of selection. 
For induction of cell death, EL4 cells and mutants thereof or L929 cells were incubated with doxorubicin (Sigma) or $\mathrm{TNF} \alpha$ for $24 \mathrm{~h}$ and cell death was analysed by phosphatidyl serine (PS) exposure on plasma membrane (Annexin V staining) and incorporation of 7-AAD by flow cytometry with a FACSCalibur (BD Pharmingen) and CellQuest software as described previously [66]. In some cases, the general caspase inhibitors Z-VAD-fmk (Bachem; $100 \mathrm{mM}$ ) or Q-VD-OpH (Tonbo Biosciences; $30 \mu \mathrm{M}$ ) or the RIPK1 inhibitor Nec-1 (Sigma; $30 \mu \mathrm{M}$ ) were added to cell cultures $1 \mathrm{~h}$ before the specific stimulus.

\section{Mouse vaccination and isolation of ex vivo $\mathrm{CDB}^{+} \mathrm{Tc}$ cells}

Mice were immunised with different amounts of LCMVWE i.p. (10-10 5 pfu) according to established protocols [66]. On day 8 postinfection, $\mathrm{CD}^{+}$cells were positively selected from spleen using $\alpha$-CD8-MicroBeads (Miltenyi Biotec, Germany) with a MACS (Miltenyi Biotec) and resuspended in RPMI 5\% heat-inactivated FBS before use in cytotoxic assays. Purity of selected $\mathrm{CD}^{+}$cells was assessed by FACS staining and found to be between 95 and $98 \%$.

\section{Ex vivo cytotoxicity assays}

Target cells were pre-incubated with the LCMV-derived peptide gp33 (Neosystem Laboratoire) and MACS-enriched ex vivo virus immune $\mathrm{CD}^{+} \mathrm{T}$ cells were stained with CellTracker Green (CTG; Invitrogen). Effector and target cells were incubated at a ratio of 10:1 (effector:target) at $37^{\circ} \mathrm{C}$. Subsequently, PS exposure on plasma membrane (Annexin V staining) and incorporation of 7-AAD were measured by three-colour flow cytometry in the target population (CTG negative) with a FACSCalibur (BD Pharmingen) and CellQuests software described previously [66].

IL1 $\beta$ release in cell culture supernatants was quantified using a Ready-SET-Go! ELISA Set from eBioscience

\section{In vivo peritoneal killing assay}

For in vivo cytotoxicity assays, $5 \times 10^{5}$ cells were preincubated with or without the peptide gp33 (Neosystem Laboratoire). Gp33 $^{-}$(EL4 $\left.^{\text {CTGdim }}\right)$ and gp33 ${ }^{+}$(EL4 $^{\text {gp33.CTGhi }}$ ) cells were labelled with $0.5 \mu \mathrm{M}$ and $5 \mu \mathrm{M}$ CTG, respectively. Subsequently, a 1:1 mixture of EL4 ${ }^{\text {CTGdim }}$ and EL4 ${ }^{\text {gp 33.CTGhi }}$ cells $\left(1 \times 10^{6}\right.$ cells in total $)$ were injected i.p. in $200 \mu \mathrm{l}$ RPMI $2 \%$ heat-inactivated FCS in mice nonimmunised or immunised with LCMV as indicated. Mice were sacrificed at different time points and peritoneal cells were collected, washed in PBS, and analysed on a FACSCalibur flow cytometer (BD Biosciences). The relative elimination of EL4 ${ }^{\text {gp33.CTGhi }}$ was analysed using the formula: $1-\left(\%\right.$ EL4 ${ }^{\text {gp } 33 . C T G h i} / \%$ EL4 $\left.{ }^{\text {CTGdim }}\right) \times 100$. In some experiments mice were injected with $100 \mu \mathrm{g}$ of anti-CD8 $\beta$ mab (clon H35-17.2) or the same amount of Rat Isotype control at days $-4,-2$ and 0 before injecting EL4 cells.

\section{Tumour development}

Non-pulsed or gp33-pulsed EL4 cells were inoculated intraperitoneally (ip; $5 \times 10^{5}$ cells) or subcutaneously (sc; $2 \times 10^{5}$ cells) in mice that had been previously vaccinated or not with 10 pfu of LCMV as indicated.

i.p. tumour development was analysed by weighting the animals and monitoring development of ascites every second day. Mice were sacrificed when they reach the humane endpoint as established by the Animal Ethics Committee (10\% increase in weight or presenting signs of morbidity).

s.c. tumour development was analysed by measuring tumour volumes every second day. Volume was calculated using the equation formula, where $\mathrm{W}, \mathrm{L}$ and $\mathrm{H}$ represents the width, length and height of the tumour. Mice were sacrificed when they reach the humane endpoint as established by the Animal Ethics Committee (Volume larger than $1 \mathrm{~cm}^{3}$ or presenting signs of ulceration).

\section{Analysis of protein expression by flow cytometry}

The percentage of LCMV-immune CD8 ${ }^{+} \mathrm{T}$ cells $(\mathrm{H} 2 \mathrm{~Kb}$ gp33 tetramer, APC, Beckman and Coulter) and the percentage of $\mathrm{Lamp1}^{+}\left(\mathrm{CD} 107 \mathrm{a}+\right.$. BD Biosciences) $\mathrm{CD} 8^{+}$ $\mathrm{T}$ cells in the peritoneal lavage were analysed as described previously [21]. To analyse gzmA, gzmB and gzmK intracellular expression after LCMV vaccination, $\mathrm{CD} 8^{+}$ $\mathrm{T}$ cells were enriched from the spleen and fixed in 4\% PFA. Subsequently, cells were permeabilized with $0.1 \%$ saponin and 5\% FBS in PBS and incubated with the $\alpha$-gzmA, $\alpha$-gzmB or $\alpha$-gzmK antibodies or with rabbit IgG isotype control, followed by $\alpha$-rabbit-Alexa 488 secondary antibody (Invitrogen) [21]. Cells were resuspended in 1\% PFA and gzms expression was analysed by FLOW CYTOMETRY.

\section{Analysis of protein expression by immunoblot}

$5 \times 10^{5}$ cells were washed in PBS and lysed in a buffer containing $1 \%$ Triton X-100 during $15 \mathrm{~min}$ on ice. Soluble protein fractions were recovered by centrifugation and separated by sodium dodecyl sulphate-polyacrylamide gel electrophoresis. Then, proteins were transferred to a PVDF membrane and blocked with 5\% fat-free milk. Anti-Bcl- $\mathrm{X}_{\mathrm{L}}$ polyclonal (1/1000; Santa Cruz), Anti-PARP-1 monoclonal $(1 / 1000 ;$ Enzo) and anti-b-actin monoclonal antibodies (1/10000; Sigma) were incubated overnight at $4{ }^{\circ} \mathrm{C}$. Then, after a washing step, membranes were incubated during $1 \mathrm{~h}$ 
at room temperature with secondary $\alpha$-rabbit or $\alpha$-mouse (respectively) IgG antibodies conjugated with HRP (Sigma) at a $1 / 20000$ dilution.

\section{Statistical analysis}

Statistical analysis was performed using GraphPad Prism software. The difference between means of unpaired samples was performed using two-way analysis of variance with Bonferroni's post-test or using unpaired $t$-test as indicated. Survival curves were compared using Log-rank test (Mantel-Cox). The results are given as the confidence interval with $P$ values and are considered significant when $P<0.05$.

Acknowledgements We would like to thank Daniele Lecis for kindly providing the SMAC mimetic SM-83. This work was supported in part by Fondo Social Europeo (JP) and Ministerio de Economia y Competitividad (SAF2011-25390 (JP), SAF2014-54763-C2-1 (JP) and SAF2017-83120-C2-1-R). Predoctoral grants/contracts from Fundación Santander/Universidad de Zaragoza (LS and MA), Gobierno de Aragon (DM, LS and PJS) and FPU/Ministerio de Educación, Cultura y Deportes (PML). IUM was supported by Fondo Garantía Empleo Juvenil/INAEM. Julián Pardo was supported by Fundación Aragon I + D (ARAID). Authors would like to acknowledge the use of Servicios Científico Técnicos del CIBA (IACS-Universidad de Zaragoza) and Servicios Apoyo Investigación de la Universidad de Zaragoza.

\section{Compliance with ethical standards}

Conflict of interest The authors declare that they have no conflict of interest.

\section{References}

1. Voskoboinik I, Whisstock JC, Trapani JA. Perforin and granzymes: function, dysfunction and human pathology. Nat Rev Immunol. 2015;15:388-400.

2. Martinez-Lostao L, Anel A, Pardo J. How Do Cytotoxic Lymphocytes Kill Cancer Cells? Clin Cancer Res. 2015;21:5047-56.

3. Afonina IS, Cullen SP, Martin SJ. Cytotoxic and non-cytotoxic roles of the CTL/NK protease granzyme B. Immunol Rev. 2010;235:105-16.

4. Trapani JA, Sutton VR. Granzyme B: pro-apoptotic, antiviral and antitumor functions. Curr Opin Immunol. 2003;15:533-43.

5. Joeckel LT, Bird PI. Blessing or curse? Proteomics in granzyme research. Proteom Clin Appl. 2014;8:351-81.

6. Hoves S, Trapani JA, Voskoboinik I. The battlefield of perforin/ granzyme cell death pathways. J Leukoc Biol. 2010;87:237-43.

7. Darmon AJ, Nicholson DW, Bleackley RC. Activation of the apoptotic protease CPP32 by cytotoxic T-cell-derived granzyme B. Nature. 1995;377:446-8.

8. Barry M, Heibein JA, Pinkoski MJ, Lee SF, Moyer RW, Green DR, et al. Granzyme B short-circuits the need for caspase 8 activity during granule-mediated cytotoxic T-lymphocyte killing by directly cleaving Bid. Mol Cell Biol. 2000;20:3781-94.

9. Sutton VR, Davis JE, Cancilla M, Johnstone RW, Ruefli AA, Sedelies $\mathrm{K}$, et al. Initiation of apoptosis by granzyme B requires direct cleavage of bid, but not direct granzyme B-mediated caspase activation. J Exp Med. 2000;192:1403-14.
10. Joeckel LT, Allison CC, Pellegrini M, Bird CH, Bird PI. Granzyme K-deficient mice show no evidence of impaired anti-viral immunity. Immunol Cell Biol. 2017;95:676-83.

11. Chowdhury D, Lieberman J. Death by a thousand cuts: granzyme pathways of programmed cell death. Annu Rev Immunol. 2008;26:389-420.

12. Froelich CJ, Pardo J, Simon MM. Granule-associated serine proteases: granzymes might not just be killer proteases. Trends Immunol. 2009;30:117-23.

13. Joeckel LT, Bird PI. Are all granzymes cytotoxic in vivo? Biol Chem. 2014;395:181-202.

14. Irmler M, Hertig S, MacDonald HR, Sadoul R, Becherer JD, Proudfoot A, et al. Granzyme A is an interleukin 1 betaconverting enzyme. J Exp Med. 1995;181:1917-22.

15. Metkar SS, Menaa C, Pardo J, Wang B, Wallich R, Freudenberg $\mathrm{M}$, et al. Human and mouse granzyme $\mathrm{A}$ induce a proinflammatory cytokine response. Immunity. 2008;29:720-33.

16. Joeckel LT, Wallich R, Martin P, Sanchez-Martinez D, Weber FC, Martin SF, et al. Mouse granzyme $\mathrm{K}$ has pro-inflammatory potential. Cell Death Differ. 2011;18:1112-9.

17. Arias MA, Jimenez de Bagues MP, Aguilo N, Menao S, HervasStubbs S, de Martino A, et al. Elucidating sources and roles of granzymes A and B during bacterial infection and sepsis. Cell Rep. 2014;8:420-9.

18. Santiago L, Menaa C, Arias M, Martin P, Jaime-Sanchez P, Metkar S, et al. Granzyme A Contributes to Inflammatory Arthritis in Mice Through Stimulation of Osteoclastogenesis. Arthritis Rheumatol. 2017;69:320-34.

19. Wensink AC, Hack CE, Bovenschen N. Granzymes Regulate Proinflammatory Cytokine Responses. J Immunol. 2015;194:491-7.

20. Wilson JA, Prow NA, Schroder WA, Ellis JJ, Cumming HE, Gearing LJ, et al. RNA-Seq analysis of chikungunya virus infection and identification of granzyme A as a major promoter of arthritic inflammation. PLoS Pathog. 2017;13:e1006155.

21. Pardo J, Wallich R, Martin P, Urban C, Rongvaux A, Flavell RA, et al. Granzyme B-induced cell death exerted by ex vivo CTL: discriminating requirements for cell death and some of its signs. Cell Death Differ. 2008;15:567-79.

22. Sanchez-Martinez D, Azaceta G, Muntasell A, Aguilo N, Nunez D, Galvez EM, et al. Human NK cells activated by EBV+lymphoblastoid cells overcome anti-apoptotic mechanisms of drug resistance in haematological cancer cells. Oncoimmunology. 2015;4:e991613.

23. Sanchez-Martinez D, Lanuza PM, Gomez N, Muntasell A, Cisneros E, Moraru M, et al. Activated Allogeneic NK Cells Preferentially Kill Poor Prognosis B-Cell Chronic Lymphocytic Leukemia Cells. Front Immunol. 2016;7:454.

24. Prakash MD, Munoz MA, Jain R, Tong PL, Koskinen A, Regner $\mathrm{M}$, et al. Granzyme B promotes cytotoxic lymphocyte transmigration via basement membrane remodeling. Immunity. 2014;41:960-72.

25. Cao X, Cai SF, Fehniger TA, Song J, Collins LI, Piwnica-Worms DR, et al. Granzyme B and Perforin Are Important for Regulatory $\mathrm{T}$ Cell-Mediated Suppression of Tumor Clearance. Immunity. 2007;27:635-46.

26. Aguilo JI, Anel A, Catalan E, Sebastian A, Acin-Perez R, Naval J, et al. Granzyme B of cytotoxic T cells induces extramitochondrial reactive oxygen species production via caspase-dependent NADPH oxidase activation. Immunol Cell Biol. 2010;88:545-54.

27. Degterev A, Hitomi J, Germscheid M, Ch'en IL, Korkina O, Teng $\mathrm{X}$, et al. Identification of RIP1 kinase as a specific cellular target of necrostatins. Nat Chem Biol. 2008;4:313-21.

28. Doitsh G, Galloway NL, Geng X, Yang Z, Monroe KM, Zepeda $\mathrm{O}$, et al. Cell death by pyroptosis drives CD4 T-cell depletion in HIV-1 infection. Nature. 2014;505:509-14. 
29. Vercammen D, Vandenabeele P, Beyaert R, Declercq W, Fiers W. Tumour necrosis factor-induced necrosis versus anti-Fas-induced apoptosis in L929 cells. Cytokine. 1997;9:801-8.

30. Lecis D, De Cesare M, Perego P, Conti A, Corna E, Drago C, et al. Smac mimetics induce inflammation and necrotic tumour cell death by modulating macrophage activity. Cell Death Dis. 2013;4:e920.

31. Gatti L, De Cesare M, Ciusani E, Corna E, Arrighetti N, Cominetti $\mathrm{D}$, et al. Antitumor activity of a novel homodimeric SMAC mimetic in ovarian carcinoma. Mol Pharm. 2014;11:283-93.

32. Cole DK, Pumphrey NJ, Boulter JM, Sami M, Bell JI, Gostick E, et al. Human TCR-binding affinity is governed by MHC class restriction. J Immunol. 2007;178:5727-34.

33. Stone JD, Chervin AS, Kranz DM. T-cell receptor binding affinities and kinetics: impact on T-cell activity and specificity. Immunology. 2009;126:165-76.

34. Adrain C, Duriez PJ, Brumatti G, Delivani P, Martin SJ. The cytotoxic lymphocyte protease, granzyme $\mathrm{B}$, targets the cytoskeleton and perturbs microtubule polymerization dynamics. J Biol Chem. 2006;281:8118-25.

35. Cullen SP, Adrain C, Luthi AU, Duriez PJ, Martin SJ. Human and murine granzyme B exhibit divergent substrate preferences. J Cell Biol. 2007;176:435-44.

36. Kaiserman D, Bird CH, Sun J, Matthews A, Ung K, Whisstock $\mathrm{JC}$, et al. The major human and mouse granzymes are structurally and functionally divergent. J Cell Biol. 2006;175:619-30.

37. Bleackley RC. A molecular view of cytotoxic T lymphocyte induced killing. Biochem Cell Biol. 2005;83:747-51.

38. Thomas DA, Scorrano L, Putcha GV, Korsmeyer SJ, Ley TJ. Granzyme B can cause mitochondrial depolarization and cell death in the absence of BID, BAX, and BAK. Proc Natl Acad Sci USA. 2001;98:14985-90.

39. Susanto O, Trapani JA, Brasacchio D. Controversies in granzyme biology. Tissue Antigens. 2012;80:477-87.

40. Cullen SP, Brunet M, Martin SJ. Granzymes in cancer and immunity. Cell Death Differ. 2010;17:616-23.

41. Davis JE, Smyth MJ, Trapani JA. Granzyme A and B-deficient killer lymphocytes are defective in eliciting DNA fragmentation but retain potent in vivo anti-tumor capacity. Eur J Immunol. 2001;31:39-47.

42. Pardo J, Balkow S, Anel A, Simon MM. Granzymes are essential for natural killer cell-mediated and perf-facilitated tumor control. Eur J Immunol. 2002;32:2881-7.

43. Smyth MJ, Street SE, Trapani JA. Cutting edge: granzymes A and $\mathrm{B}$ are not essential for perforin-mediated tumor rejection. J Immunol. 2003;171:515-8.

44. Revell PA, Grossman WJ, Thomas DA, Cao X, Behl R, Ratner $\mathrm{JA}$, et al. Granzyme B and the downstream granzymes $\mathrm{C}$ and/or $\mathrm{F}$ are important for cytotoxic lymphocyte functions. J Immunol. 2005;174:2124-31.

45. Ravi R, Fuchs EJ, Jain A, Pham V, Yoshimura K, Prouser T, et al. Resistance of cancers to immunologic cytotoxicity and adoptive immunotherapy via X-linked inhibitor of apoptosis protein expression and coexisting defects in mitochondrial death signaling. Cancer Res. 2006;66:1730-9.

46. Sutton VR, Wowk ME, Cancilla M, Trapani JA. Caspase activation by granzyme $\mathrm{B}$ is indirect, and caspase autoprocessing requires the release of proapoptotic mitochondrial factors. Immunity. 2003;18:319-29.

47. Casciola-Rosen L, Garcia-Calvo M, Bull HG, Becker JW, Hines $\mathrm{T}$, Thornberry NA, et al. Mouse and human granzyme B have distinct tetrapeptide specificities and abilities to recruit the Bid pathway. J Biol Chem. 2006;282:4545-52.
48. Casciola-Rosen L, Garcia-Calvo M, Bull HG, Becker JW, Hines $\mathrm{T}$, Thornberry NA, et al. Mouse and human granzyme B have distinct tetrapeptide specificities and abilities to recruit the bid pathway. J Biol Chem. 2007;282:4545-52.

49. Sutton VR, Vaux DL, Trapani JA. Bcl-2 prevents apoptosis induced by perforin and granzyme $\mathrm{B}$, but not that mediated by whole cytotoxic lymphocytes. J Immunol. 1997;158:5783-90.

50. Melero I, Berman DM, Aznar MA, Korman AJ, Perez Gracia JL, Haanen J. Evolving synergistic combinations of targeted immunotherapies to combat cancer. Nat Rev Cancer. 2015;15:457-72.

51. Pardoll DM. The blockade of immune checkpoints in cancer immunotherapy. Nat Rev Cancer. 2012;12:252-64.

52. Franklin C, Livingstone E, Roesch A, Schilling B, Schadendorf D. Immunotherapy in melanoma: Recent advances and future directions. Eur J Surg Oncol. 2017;43:604-11.

53. Kumar R, Collins D, Dolly S, McDonald F, O’Brien MER, Yap TA. Targeting the PD-1/PD-L1 axis in non-small cell lung cancer. Curr Probl Cancer. 2017;41:111-24.

54. Malhotra J, Jabbour SK, Aisner J. Current state of immunotherapy for non-small cell lung cancer. Transl Lung Cancer Res. 2017:6:196-211.

55. Wolchok JD. PD-1 Blockers. Cell. 2015;162:937.

56. Buchbinder EI, Desai A. CTLA-4 and PD-1 Pathways: Similarities, Differences, and Implications of Their Inhibition. Am J Clin Oncol. 2016;39:98-106.

57. Heere-Ress E, Thallinger C, Lucas T, Schlagbauer-Wadl H, Wacheck V, Monia BP, et al. Bcl-X(L) is a chemoresistance factor in human melanoma cells that can be inhibited by antisense therapy. Int J Cancer. 2002;99:29-34.

58. Leiter U, Schmid RM, Kaskel P, Peter RU, Krahn G. Antiapoptotic bcl-2 and bcl-xL in advanced malignant melanoma. Arch Dermatol Res. 2000;292:225-32.

59. Zhang H, Rosdahl I. Bcl-xL and bcl-2 proteins in melanoma progression and UVB-induced apoptosis. Int $\mathrm{J}$ Oncol. 2006;28:661-6.

60. Zhuang L, Lee CS, Scolyer RA, McCarthy SW, Zhang XD, Thompson JF, et al. Mcl-1, Bcl-XL and Stat3 expression are associated with progression of melanoma whereas Bcl-2, AP-2 and MITF levels decrease during progression of melanoma. Mod Pathol. 2007;20:416-26.

61. Karczmarek-Borowska B, Filip A, Wojcierowski J, Smolen A, Korobowicz E, Korszen-Pilecka I, et al. Estimation of prognostic value of Bcl-xL gene expression in non-small cell lung cancer. Lung Cancer. 2006;51:61-69.

62. Park D, Magis AT, Li R, Owonikoko TK, Sica GL, Sun SY, et al. Novel small-molecule inhibitors of Bcl-XL to treat lung cancer. Cancer Res. 2013;73:5485-96.

63. Sanchez-Ceja SG, Reyes-Maldonado E, Vazquez-Manriquez ME, Lopez-Luna JJ, Belmont A, Gutierrez-Castellanos S. Differential expression of STAT5 and Bcl-xL, and high expression of Neu and STAT3 in non-small-cell lung carcinoma. Lung Cancer. 2006;54:163-8.

64. Schmidt LH, Kummel A, Gorlich D, Mohr M, Brockling S, Mikesch JH, et al. PD-1 and PD-L1 Expression in NSCLC Indicate a Favorable Prognosis in Defined Subgroups. PLoS One. 2015;10:e136023.

65. Riedl SJ, Renatus M, Snipas SJ, Salvesen GS. Mechanism-based inactivation of caspases by the apoptotic suppressor p35. Biochemistry. 2001;40:13274-80.

66. Catalan E, Jaime-Sanchez P, Aguilo N, Simon MM, Froelich CJ, Pardo J. Mouse cytotoxic T cell-derived granzyme B activates the mitochondrial cell death pathway in a Bim dependent fashion. $\mathrm{J}$ Biol Chem. 2014;290:6868-77. 